\title{
Conservative treatment cures an elderly pituitary apoplexy patient with oculomotor paralysis and optic nerve compression: a case report and systematic review of the literature
}

This article was published in the following Dove Press journal:

Clinical Interventions in Aging

\section{Yanghua Fan \\ Xinjie Bao \\ Renzhi Wang}

Department of Neurosurgery, Peking Union Medical College Hospital, Chinese Academy of Medical Sciences and Peking Union Medical College, Beijing, China
Correspondence: Xinjie Bao;

Renzhi Wang

Department of Neurosurgery, Pituitary Center, Peking Union Medical College Hospital, Chinese Academy of Medical Sciences, No I Shuaifuyuan, Dongcheng District, Beijing 100730, China

$\mathrm{Tel}+86 \quad$ I80 01 I8 2406

Fax+8601069I5 2530

Email xinjieabao@।63.com;

wangrz@126.com
Background: Whether conservative treatment or surgical management is the most appropriate treatment for pituitary apoplexy (PA) is controversial. In general, if severe symptoms of compression occur, such as oculomotor nerve palsy, neurosurgery is performed to relieve the compression of anatomical structures near the PA.

Case description: We describe the case of a 79-year-old man who was found to have an intrasellar pituitary incidentaloma. The tumor was discovered accidentally, during an investigation into the cause of his dizziness. Two months later, he suddenly developed headaches, left ophthalmoplegia, decreased vision, severe blepharoptosis and diplopia. He was diagnosed with PA and hypocortisolemia based on magnetic resonance imaging (MRI) and blood tests, respectively. His symptoms of oculomotor palsy and optic nerve compression were serious, but his ophthalmological deficits were nonprogressive and his hormone levels improved through conservative treatment (hydrocortisone supplementation). Due to this older patient's poor physical condition and serious coronary heart disease, after multidisciplinary consultation and according to his family's wishes, we continued the conservative treatment and watched closely for any changes in the patient's condition. After 6 months of conservative treatment, the patient's symptoms of oculomotor nerve paralysis, pupil and vision defects completely disappeared, and no new complications occurred. Repeated MRI tests showed that the PA lesion gradually improved. The patient's hypocortisolemia was completely relieved through oral supplementation with low-dose hydrocortisone.

Conclusion: In older PA patients who have surgical contraindications, even with symptoms of compression, such as oculomotor nerve palsy, according to the international guidelines, if conservative treatment is effective and the condition is not progressing, it is possible to monitor patients' condition closely and continue conservative treatment, which may yield good results.

Keywords: pituitary apoplexy, oculomotor paralysis, conservative treatment

\section{Introduction}

Pituitary apoplexy (PA) is a potentially life-threatening clinical syndrome, comprising sudden onset of headaches, oculomotor paralysis, visual deficits, hormonal dysfunction and altered consciousness. ${ }^{1,2}$ It can result from hemorrhage or infarction of the pituitary gland.

Although many experts have investigated treatments for PA, it remains controversial whether conservative treatment or surgical management is the most appropriate treatment choice. ${ }^{3}$ We report the case of an elderly patient with PA, characterized 
by headache, ophthalmoplegia, severe blepharoptosis, diplopia and visual disturbances, whose symptoms completely resolved through conservative treatment of hypopituitarism, which is a complication of PA.

\section{Case description}

A 79-year-old man had suffered from dizziness for 5 months. He had severe coronary heart disease for 20 years, but he had not been treated with oral anticoagulants. Magnetic resonance imaging (MRI) scans of the brain revealed an intrasellar pituitary incidentaloma (Figure 1). His pituitary hormone test results were normal except for a low level of testosterone $(0.20 \mathrm{ng} / \mathrm{mL})$. No treatment was initiated at that time, because there were no pituitary-related symptoms.

Two months after the discovery of the pituitary tumor, the patient suddenly had severe headache, left diplopia, eyelid ptosis and visual dysfunction. On neurological examination, restriction of medial, downward and upward movement of the left eye was observed, indicating left oculomotor nerve palsy. His left pupil was enlarged (approximately $5 \mathrm{~mm}$ ) and unresponsive to light. Visual acuity in his left eye was significantly decreased and visual field defects were present, indicating optic nerve compression. Laboratory tests of the patient's pituitary hormones revealed that the adrenocorticotropic hormone $(\mathrm{ACTH},<5.00 \mathrm{pg} / \mathrm{mL})$, cortisol $(0.71 \mu \mathrm{g} / \mathrm{dL})$ and testosterone levels were all low. His testosterone level $(0.18 \mathrm{ng} / \mathrm{mL})$ was similar to the results 2 months earlier. The levels of his other pituitary hormones, such as growth hormone $(\mathrm{GH})$, thyroid-stimulating hormone (TSH) and prolactin (PRL), were normal. The patient's pituitary hormone test results improved after he was treated with hydrocortisone as described in the following paragraphs.

T1-weighted MRI showed a large soft tissue mass with high signal intensity, and T2-weighted MRI showed a hybrid intensity mass in the saddle area, suggesting apoplexy (Figure 2A). The mass compressed the left cavernous sinus. Contrast-enhanced MRI showed that the mass had an uneven enhancement pattern. These imaging findings indicated that the patient had PA.

The symptoms of oculomotor palsy and optic nerve compression were serious in this patient. Due to his poor health and coronary heart disease, the risk of surgery was very high for this patient. His hormone levels improved (cortisol, $4.14 \mu \mathrm{g} / \mathrm{dL}$ ), and his ophthalmological deficits were nonprogressive with medical treatment and hormone replacement for hypopituitarism. Therefore, after multidisciplinary consultations and according to his family's wishes, we continued the conservative treatment and monitored the patient closely for any change in his condition. During a 6-month follow-up period, the patient's treatments were administered as follows: $100 \mathrm{mg}$ of hydrocortisone intravenously once a day initially, then 2 weeks later changed to $20 \mathrm{mg}$ of oral hydrocortisone two times per day, and then gradually reduced to his ongoing oral hydrocortisone dose of $20 \mathrm{mg}$ daily. The patient's MRI scans taken after 2 months (Figure 2B) and 5 months (Figure 2C) of conservative treatment showed gradual improvement in the PA. His symptoms also gradually improved.

After 6 months of conservative treatment, the patient's symptoms of headache, oculomotor nerve paralysis, pupillary defect and reduced vision had completely disappeared, without new complications. The patient's current cortisol levels are normal with ongoing oral hydrocortisone.

\section{Discussion}

The neurologist Pearce Bailey published the first description of this disease. In 1950, the neurosurgeon Milton Brougham first proposed the term "pituitary apoplexy",

\section{T2-weighted coronal}

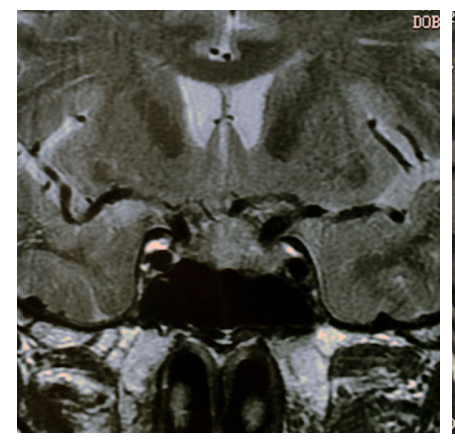

T1-weighted coronal

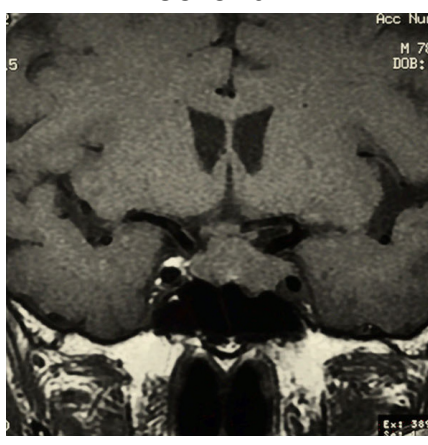

T1-weighted sagittal

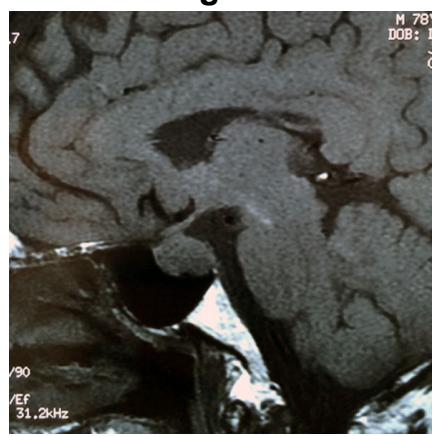

Figure I Pituitary incidentaloma detected accidentally, during an MRI examination for dizziness

Abbreviation: MRI, magnetic resonance imaging. 


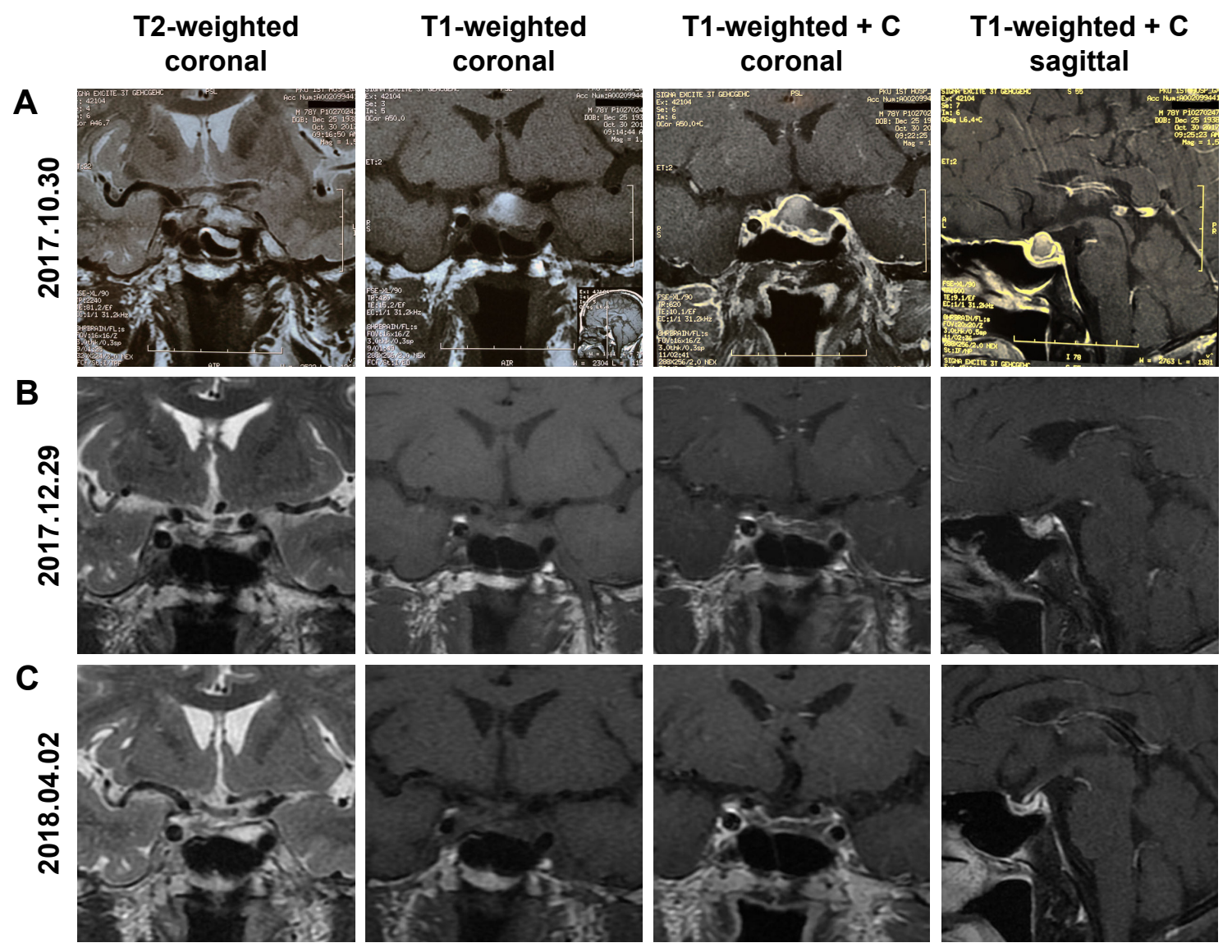

Figure 2 (A) Consistent with the patient's headache and oculomotor palsy, PA was diagnosed on MRI. (B, C) MRI results after 2 months (B) and 5 months (C) of conservative treatment. Repeated MRI tests showed that the PA lesion gradually improved. $+C$ Contrast-enhanced MRI.

Abbreviations: MRI, magnetic resonance imaging; PA, pituitary apoplexy.

thus emphasizing the acute and severe clinical manifestations of this disease. ${ }^{4}$

PA is a clinical syndrome consisting of endocrine abnormalities and neurological deficits caused by underlying pituitary adenoma hemorrhage and/or ischemia, resulting in expansion, edema and necrosis. ${ }^{5,6}$ The clinical manifestations of PA are diverse. Anterior pituitary hormone deficiency, especially ACTH deficiency, is prone to cause electrolyte disturbances, nausea and vomiting. Endocrinopathy, in the form of partial- or pan-hypopituitarism, is also commonly encountered. Severe glandular compression after intratumoral hemorrhage, or intracerebral content necrosis after ischemia, may lead to partial or systemic hypopituitarism. In the case of mild clinical symptoms, PA can be diagnosed as a "chance finding", either intraoperatively, histopathologically or on MRI. ${ }^{7}$

The mechanism leading to apoplexy into pituitary macroadenomas is not completely clear. The origin of PA can be as follows: pituitary adenoma-related (large size or cavernous invasive), treatment-related (bromocriptine, surgery or radiation) or pituitary dynamic test-related (gonadotropin or thyrotropin-releasing hormone). Diabetes mellitus, changes in intracranial pressure, cerebral angiography, hypertension, thrombolytic therapy and head trauma have also been identified as potential risk factors for PA. ${ }^{8-10}$ None of these relevant factors were present in this patient.

Pituitary adenoma rarely causes oculomotor nerve palsy, but PA does. Neurological deficits can be directly attributed to increased sphenoid sinus pressure, due to acute enlargement of the pituitary adenoma and mass effects on adjacent cranial nerves. ${ }^{11}$ The visual field deficits and decreased visual acuity are caused by suprasellar expansion with pressure on the optic chiasm or optic nerves. The III, IV and VI cranial nerves may experience compression, and diplopia, ophthalmoplegia and ptosis usually occur within a few hours after the onset of headache. ${ }^{12}$ Our patient presented with a complete and abrupt paralysis of the left oculomotor nerve associated with left diplopia, ptosis, mydriasis and ophthalmoplegia. In most cases, and according to the natural course of PA, surgical treatment is unnecessary because tumors usually diminish, and even disappear, without surgical intervention. ${ }^{13}$ Patients with severe neurological or ophthalmic impairment 
may have a slightly worse prognosis, but if correctly handled, the symptoms can show remarkable improvement. ${ }^{14}$ Because rebleeding and tumor recurrence can occur regardless of conservative or surgical treatment, pituitary MRI should be repeated every 3-6 months for 5 years, and then every 6 months thereafter. ${ }^{15}$

Early diagnosis and treatment of PA are very important for avoiding complications and preventing persistent ophthalmic defects. ${ }^{10,16}$ However, the best treatment for PA (surgery or conservative) has long been controversial. To date, no large-scale, prospective randomized studies comparing surgical treatment with conservative management for PA are available. ${ }^{17-19}$ Some studies have indicated that emergent neurosurgical decompression should be the first choice, especially when there are serious neurologic deficits. ${ }^{3,20}$ Leyer et $\mathrm{al}^{21}$ advocated for conservative management, especially when the ophthalmic defect is mild and nonprogressive.

Notwithstanding the controversy, the initial medical care should include replacement of hormones, treatment with steroids and treatment for metabolic deficiencies. ${ }^{22,23}$ Because of hypocortisolemia after PA, this patient was treated with hydrocortisone, and his pituitary hormone levels completely normalized.

What kind of treatment should be implemented next, surgical or nonsurgical? Recently, some studies have shown that there are no significant differences between the outcomes for patients with surgery and for those with conservative treatment, if conservative treatment was restricted to patients with nonprogressive and mild ophthalmological deficits. There was improvement in, or complete resolution of, the patients' visual deficits in $80 \%-100 \%$ of these cases. ${ }^{19,24}$ Others have also reported that about $90 \%$ of patients with PA can achieve good results by surgery or conservative treatment. ${ }^{11,22}$ Some studies have concluded that endocrine function after PA surgery often remains abnormal, with a worse outcome compared with that of surgically treated patients with nonapoplexy pituitary adenomas. However, most studies have shown that surgery is usually performed within 7 days after $\mathrm{PA}$, and the recovery rate of visual impairment is higher than with conservative treatment. ${ }^{13,25}$ A recent systematic review suggested that surgically treated patients had a significantly higher rate of recovery from ocular palsy and reduced visual fields, so surgical intervention is advised for PA patients with visual field defects and ocular palsy. ${ }^{3}$

According to the latest clinical guideline for diagnosis and treatment of $\mathrm{PA}$, when patients have severe neuro-ophthalmic signs, neurosurgery should be considered. ${ }^{26}$ However, in the present case, the risk of surgery was very high. Moreover, the patient's hormone levels improved and his ophthalmological deficits were nonprogressive with medical treatment and hormonal replacement for hypopituitarism. Therefore, after consulting with physicians across disciplines and with the patient's family members, we continued the conservative treatment and paid close attention to the patient's condition. After 6 months of conservative treatment, the patient's symptoms of oculomotor nerve paralysis and pupil and vision defects completely disappeared and no new complications occurred. Repeated MRI tests showed that the PA lesion gradually improved. Hypocortisolemia completely resolved after oral supplementation with low-dose hydrocortisone.

\section{Conclusion}

The decision on treatment modality was based on neurologic deficits and initial evolution. This patient with nonprogressive deficits improved after initial hydrocortisone treatment, but for elderly PA patients with such severe symptoms, the likelihood of achieving complete remission with conservative treatment is very low. However, the present case demonstrates that in older PA patients who have symptoms of compression, but for whom surgery is contraindicated, in accordance with the international guidelines, if conservative treatment is effective and the condition is not progressing, it is possible to monitor the patient's condition closely and continue conservative treatment, which may yield good results. This case provides new insights relevant to future treatment of older PA patients who have other organic diseases and are at a high risk for surgery.

\section{Ethics statement}

The patient provided written informed consent for the case and accompanying images to be published. This case report was approved by the ethical review committee of the Peking Union Medical College Hospital.

\section{Abbreviations}

PA, pituitary apoplexy; MRI, magnetic resonance imaging; ACTH, adrenocorticotropic hormone.

\section{Acknowledgments}

This work was supported by the Capital Medical Development Research Foundation of China (grant no 2016-1-4012). We thank Claire Barnes, PhD, from Liwen Bianji, Edanz Editing China, for editing the English text of a draft of this manuscript. 


\section{Disclosure}

The authors report no conflicts of interest in this work.

\section{References}

1. Randeva HS, Schoebel J, Byrne J, Esiri M, Adams CB, Wass JA. Classical pituitary apoplexy: clinical features, management and outcome. Clin Endocrinol. 1999;51(2):181-188.

2. Semple PL, Webb MK, de Villiers JC, Laws ER. Pituitary apoplexy. Neurosurgery. 2005;56(1):65-73.

3. Tu M, Lu Q, Zhu P, Zheng W. Surgical versus non-surgical treatment for pituitary apoplexy: A systematic review and meta-analysis. J Neurol Sci. 2016;370:258-262.

4. Brougham M, Heusner AP, Adams RD. Acute degenerative changes in adenomas of the pituitary body - with special reference to pituitary apoplexy. J Neurosurg. 1950;7(5):421-439.

5. Rutkowski MJ, Kunwar S, Blevins L, Aghi MK. Surgical intervention for pituitary apoplexy: an analysis of functional outcomes. J Neurosurg. 2018;129(2):417-424.

6. Onesti ST, Wisniewski T, Post KD. Clinical versus subclinical pituitary apoplexy: presentation, surgical management, and outcome in 21 patients. Neurosurgery. 1990;26(6):980-986.

7. Laws ER. Pituitary tumor apoplexy: a review. J Intensive Care Med. 2008;23(2):146-147.

8. Bi WL, Dunn IF, Laws ER. Pituitary apoplexy. Endocrine. 2015;48(1): 69-75.

9. Liu ZH, Chang CN, Pai PC, et al. Clinical features and surgical outcome of clinical and subclinical pituitary apoplexy. J Clin Neurosci. 2010;17(6):694-699.

10. Turgut M, Ozsunar Y, Başak S, Güney E, Kir E, Meteoğlu I. Pituitary apoplexy: an overview of 186 cases published during the last century. Acta Neurochir. 2010;152(5):749-761.

11. Hage R, Eshraghi SR, Oyesiku NM, et al. Third, Fourth, and Sixth Cranial Nerve Palsies in Pituitary Apoplexy. World Neurosurg. 2016; 94:447-452.

12. Berthelot JL, Rey A. Pituitary apoplexy. Presse Med. 1995;24(10): 501-503.

13. Wildemberg LE, Glezer A, Bronstein MD, Gadelha MR. Apoplexy in nonfunctioning pituitary adenomas. Pituitary. 2018;21(2):138-144.
14. Albani A, Ferraù F, Angileri FF, et al. Multidisciplinary Management of Pituitary Apoplexy. Int J Endocrinol. 2016;2016:7951536.

15. Boellis A, di Napoli A, Romano A, Bozzao A. Pituitary apoplexy: an update on clinical and imaging features. Insights Imaging. 2014;5(6): $753-762$.

16. Kim SH, Lee KC, Kim SH. Cranial nerve palsies accompanying pituitary tumour. J Clin Neurosci. 2007;14(12):1158-1162.

17. Zhang RC, Mu YF, Dong J, Lin XQ, Geng DQ. Complex effects of apoplexy secondary to pituitary adenoma. Rev Neurosci. 2017;28(1):59-64.

18. Zaidi HA, Cote DJ, Burke WT, et al. Time Course of Symptomatic Recovery After Endoscopic Transsphenoidal Surgery for Pituitary Adenoma Apoplexy in the Modern Era. World Neurosurg. 2016;96: 434-439.

19. Giritharan S, Gnanalingham K, Kearney T. Pituitary apoplexy-bespoke patient management allows good clinical outcome. Clin Endocrinol. 2016;85(3):415-422.

20. Chuang CC, Chang CN, Wei KC, et al. Surgical treatment for severe visual compromised patients after pituitary apoplexy. J Neurooncol. 2006;80(1):39-47.

21. Leyer C, Castinetti F, Morange I, et al. A conservative management is preferable in milder forms of pituitary tumor apoplexy. J Endocrinol Invest. 2011;34(7):502-509.

22. Singh TD, Valizadeh N, Meyer FB, Atkinson JL, Erickson D, Rabinstein AA. Management and outcomes of pituitary apoplexy. J Neurosurg. 2015;122(6):1450-1457.

23. Oldfield EH, Merrill MJ. Apoplexy of pituitary adenomas: the perfect storm. J Neurosurg. 2015;122(6):1444-1449.

24. Grzywotz A, Kleist B, Möller LC, et al. Pituitary apoplexy - A single center retrospective study from the neurosurgical perspective and review of the literature. Clin Neurol Neurosurg. 2017;163:39-45.

25. Abdulbaki A, Kanaan I. The impact of surgical timing on visual outcome in pituitary apoplexy: Literature review and case illustration. Surg Neurol Int. 2017;8:16

26. Vicente A, Lecumberri B, Gálvez MÁ; Grupo de Trabajo de Neuroendocrinología. Clinical practice guideline for the diagnosis and treatment of pituitary apoplexy. Endocrinol Nutr. 2013;60(10):582.e1-582.e12.
Clinical Interventions in Aging

\section{Publish your work in this journal}

Clinical Interventions in Aging is an international, peer-reviewed journal focusing on evidence-based reports on the value or lack thereof of treatments intended to prevent or delay the onset of maladaptive correlates of aging in human beings. This journal is indexed on PubMed Central, MedLine,

\section{Dovepress}

CAS, Scopus and the Elsevier Bibliographic databases. The manuscript management system is completely online and includes a very quick and fair peer-review system, which is all easy to use. Visit http://www.dovepress. com/testimonials.php to read real quotes from published authors. 